\title{
The sociophonetics of rhotic variation in Sicilian dialects and Sicilian Italian: corpus, methodology and first results
}

\author{
Chiara Celata, Chiara Meluzzi and Irene Ricci \\ Scuola Normale Superiore, Pisa \\ chiara.celata@sns.it, chiara.meluzzi@sns.it, irene.ricci@sns.it
}

\begin{abstract}
Submitted: 30/10/2015. Accepted: 18/01/2016. Available on line: 29/09/2016
Citation / Cómo citar este artículo: Celata, C., Meluzzi, C. and Ricci, I. (2016). The sociophonetics of rhotic variation in Sicilian dialects and Sicilian Italian: corpus, methodology and first results. Loquens, 3(1), e025. doi: http://dx.doi. org/10.3989/loquens.2016.025
\end{abstract}

\begin{abstract}
SoPhISM (The SocioPhonetics of verbal Interaction: Sicilian Multimodal corpus) is an acoustic and articulatory sociophonetic corpus focused on whithin-speaker variation as a function of stylistic/communicative factors. The corpus is particularly intended for the study of rhotics as a sociolinguistic variable in the production of Sicilian speakers. Rhotics are analyzed according to the distinction between single-phase and multiple-phase rhotics along with the presence of constriction and aperture articulatory phases. Based on these parameters, the annotation protocol seeks to classify rhotic variants within a sufficiently granular, but internally consistent, phonetic perspective. The proposed descriptive parameters allow for the discussion of atypical realizations in terms of phonetic derivations (or simplifications) of typical closure-aperture sequences. The distribution of fricative variants in the speech repertoire of one speaker and his interlocutors shows the potential provided by SoPhISM for sociophonetic variation to be studied at the 'micro' level of individual speaker's idiolects.
\end{abstract}

Keywords: rhotics; articulatory sociophonetics; phonetic annotation; coda /r/; Sicilian.

RESUMEN: Sociofonética de la variación de las róticas en los dialectos sicilianos y en el italiano de Sicilia: corpus, metodología y primeros resultados.- SoPhISM (SocioPhonetics of verbal Interaction: Sicilian Multimodal corpus) es un corpus sociofonético acústico y articulatorio centrado en la variación individual en función de la variedad de la lengua y de los factores estilísticos y comunicativos del habla. El corpus está concebido particularmente para el estudio de /r/ en cuanto variable sociolingüística en el habla italiana y dialectal de locutores sicilianos. Las róticas se analizan teniendo en cuenta la distinción entre monofásicas y multifásicas, y la presencia de fases de constricción y abertura. Sobre la base de estos parámetros, el protocolo de anotación intenta clasificar las variantes dentro de una perspectiva fonética suficientemente minuciosa y, al mismo tiempo, internamente coherente. Los parámetros descriptivos propuestos permiten discutir ciertas realizaciones atípicas como derivaciones fonéticas (o simplificaciones) de secuencias típicas de cierre-apertura. La distribución de las variantes fricativas en el repertorio de un hablante y de sus interlocutores muestra el potencial proporcionado por SoPhISM para el estudio de la variación sociofonética en el nivel "micro" de los idiolectos.

Palabras clave: róticas; sociofonética articulatoria; anotación fonética; /r/ en coda; siciliano.

\section{INTRODUCTION}

Within the variety of "dialect/standard constellations" (Auer, 2005) currently emerging in Europe, Italy appears to be a very peculiar linguistic landscape. The dynamics of dialect/standard contact (including phenomena of demotization and de-/re-standardization; Coupland and Kristiansen, 2011; Ammon, 2003; Berruto, 1987) has acquired in the Peninsula idiosyncratic features that cannot be entirely reconciled with models elaborated for other European languages (see Cerruti, Crocco, \& Marzo, in press). The reasons for this peculiarity are historical and socio-cultural. They stem from the presence of primary dialects (Coseriu, 1980) whose evolutions have paralleled the spreading of the national language alongside a variety of stances by different parts of the population on the use and transmission of local dialects. 
Assuming a sociophonetic perspective on intra-speaker variation, this research approaches the issue of how Italian speakers with strong dialectal backgrounds exploit their stratified linguistic-phonetic repertoire in order to convey extralinguistic meaning about social behaviors and communicative needs. In the following sections, we will explain the theoretical motivations and goals of the research project (Section 2), present the nature and structure of the speech corpus (Section 3), discuss methodological challenges concerning the phonetic annotation of intra-speaker variation for rhotic production (Section 4), and give a preliminary analysis of the distribution of the fricative variants in the speech repertoire of one speaker (Section 5). In the final discussion (Section 6), we outline the implications of the current analysis for the phonetics/ phonology of rhotics and offer perspectives for further research development.

\section{SOCIOPHONETICS IN THE ITALO-ROMANCE DOMAIN}

The study is aimed at documenting rhotic variation as a function of socio-communicative and stylistic factors in the individual linguistic repertoires of young dialectal Italian speakers. The study is based on SoPhISM (The SocioPhonetics of verbal Interaction: Sicilian Multimodal corpus), a multi-level acoustic and articulatory corpus that will be detailed in Section 3. Rather than variation and innovation as stemming from contact among linguistic varieties, the focus of our approach is on variation/innovation originating from the way the speakers exploit subtle pronunciation cues to meet concrete social and communicative requirements (Eckert, 2012; Giles, 1994; Johnstone, Andrus, \& Danielson, 2006).

The interest in analyzing variation as a continuum of socio-communicative possibilities, rather than as the result of an intersection of two or more pre-defined 'varieties', originates from the observation that Italian speakers are not bilingual in the classical sense. Historically and structurally, the repertoire is based on two polar linguistic codes (Italian versus the local Romance dialect), involved in either a diglossic or a dilalic relationship (Berruto, 1989). However, the re-use of former geographical differentiation as a social and communicative resource by the new generations of Italian dialectophones has given rise to new ways of manipulating the possibilities offered by the repertoire (e.g., Cerruti, 2011; Crocco, in press; Dal Negro \& Vietti, 2011), but also to new psychological and ideological positions towards variation (e.g., De Pascale, Marzo, \& Speelman, 2016).

Pronunciation and intonation variants have a straightforward role in the construction of a social identity for individuals, and particularly so for the youngest generations (e.g., Lawson, 2011; Mendoza-Denton, 2008).

During the last few decades, Sicily is one of the territories in which the number of people affirming to make use of both Italian and the local Romance dialect (for both formal and informal communicative situations) has systematically grown (with the exclusion of the regional head town, Palermo; D'Agostino \& Paternostro, 2013). Although the Sicilian dialect is no longer the sole maternal language for the majority of children in this region, the former anti-dialectal prejudice that was once diffused all across the country is now being overturned. New forms of utilizing dialectal resources for written and oral communication are diffused among the younger generations. Furthermore, like in most Italian territories, the regionally accented variety of Italian has been consolidating its status in the recent decades (e.g., Crocco, in press) as a result of a progressive demotization process. Crucially for our purposes, the alternate use of dialect and regional Italian lacks systematic documentation, especially for pronunciation. Other authors, while commenting upon the sociological questionnaires used to elicit a speaker's opinions about his own communicative choices, have precisely pointed out that research in this domain is scarce. For example, after considering the responses given to the survey question "Do you usually speak Italian, the dialect, or both with members of your family / peers and friends / the elderly", etc., D'Agostino and Paternostro $(2013$, p. 476) conclude that "the category of 'both' is, by itself, too vague to provide any indication of the forms assumed by this co-presence, as it may have very different characteristics [across speakers]" (our translation). Similarly, according to Dal Negro and Vietti (2011), "[one] problematic issue[], that could not be fully addressed here, concern[s] . . . the combined use of Italian and dialect, which may be understood by speakers as either a (more or less) simultaneous combination or as an alternated use of the two languages" (our italicization). Similar opinions are mostly based on empirical evidence concerning written uses such as graffiti, advertisements, SMS and popular posters (for Sicilian cases, see Alfonzetti, 2013; D'Agostino \& Paternostro, 2013). The sociophonetic aspects of this complex repertoire have been under studied, although recent inquiries are being developed in this direction (e.g., Felloni, 2011; Meluzzi, 2014, 2016; Nodari, in preparation). The observation of fine-grained aspects of intra-speaker variation is expected to help our understanding of how much variation is tolerated in an individual's speech and for which socio-indexical and communicative purposes such variations are used.

\section{THE SOPHISM CORPUS AND THE ANNOTATION PROTOCOL}

SoPhISM is an acoustic and articulatory sociophonetic corpus focused on intra-speaker variation as a function of language variety and stylistic/communicative factors. It documents several speech varieties and styles produced by fluently 'bilingual' Sicilian-Italian speakers under the age of 30 from the Modica (Ragusa) and Enna areas. Although SoPHISM allows for the investigation of a large range of pronunciation features, the corpus is primarily targeted at the analysis of the ' $R$ ' variable (Scobbie, 2006). 
In Sicilian dialects and Sicilian regional Italian, two phenomena are said to be particularly relevant for ' $R$ '. The first one is the realization of the ' $(\mathrm{t}) \mathrm{tr}$ ' cluster as an apical postalveolar / retroflex affricate (see Celata, 2006; Ruffino, 2001). It has been claimed that this pronunciation feature is very salient to the metalinguistic consciousness of the speakers; being classified as strongly dialectal and/or vernacular, it also acts as a marker of local provenance. The second phenomena is the realization of the prevocalic geminate /r:/ as a postalveolar sibilant fricative, which is usually described and/or transcribed as [zi]. In this second case, the precise articulatory configuration is less clear. Similarly more dubious and irregular is the perception of its sociolinguistic status in the metalinguistic competence of Sicilian speakers. Therefore, analyzing ' $R$ ' in the speech of Sicilian speakers allows for the comparison of sociophonetic behavior(s) in different phonetic and lexical contexts with the same variable, while highlighting potential differences in their sociocognitive status (e.g., Barbu, Martin, \& Chevrot, 2014).

The corpus is still being collected and coded. In the following sections, we will review the annotation protocol with some detail and show the complexity of annotating and classifying rhotics, within a sufficiently granular, but internally consistent, phonetic perspective. We will also show the distribution of a selection of variants in the repertoire of one speaker and his interlocutors to demonstrate the potential provided by SoPhISM for the study of sociophonetic variation at the micro level of the idiolects of individual speakers.

The corpus contains synchronized acoustic, electropalatographic (EPG) and electroglottographic (EGG) data for Sicilian male speakers between the ages of 20 and 30 years old. Currently, there are three male speakers, two of which are from Modica and one from Enna. We intend to extend the current study to a broader study of peer interactions (see e.g. Barbu et al. 2014). Each participant was recorded while speaking in both regional Italian and the local Sicilian dialect. For both language varieties, read speech and map-task-style dialogues with different interlocutors were recorded.

The map-task dialogues were achieved with three different interlocutors, who occupied three different positions in the relevant speaker's relationship. The first interlocutor, hereafter I1, was a close, childhood friend, born and raised in the same town as the speaker; the second, $\mathrm{I} 2$, was a friend from his early teens who was raised in a nearby town; the third, I3, was also a peer, but unacquainted with the relevant speaker, and of Tuscan origin. The dialogues with I3 were in Italian only, while the former two were both in Italian and in Sicilian.

This experimental design was aimed at eliciting a multidimensional continuum of speaker-specific varieties in diversified interactional contexts. These diverse contexts were the result of Italian and Sicilian linguistic variety parameters intersecting along with a formality degree parameter, or the 'style' of the interaction.

In addition, two sentence lists were recorded for each speaker, one in Italian and the other in Sicilian. For the
Sicilian sentences, preliminary work was done with each individual speaker to choose the most appropriate production according to the speaker's native variety and to find the best orthographic coding of the selected words and sentences. This was achieved thanks to the metalinguistic competence of the speakers concerning their own multilingual repertoire and that of their native community. However direct reference was never made to the realization of rhotics, and minimal reference was made to pronunciation features in general.

During the recordings, the relevant speaker sat in the soundproof room at the phonetics laboratory of Scuola Normale Superiore, Pisa, and wore an EPG artificial palate (for WinEPG3) and an EGG collar (see Figure 1). The acoustic output was recorded with a Shure microphone in front of him at a distance of about $30 \mathrm{~cm}$ ( $44 \mathrm{kHz}, 16 \mathrm{bit})$. The audio and EPG signals were automatically aligned by the AA software from ArticulateInstruments Ltd (Wrench, 2007). The EGG recordings were obtained through a

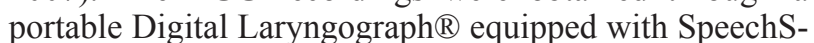
tudio. The interlocutors' speech was recorded with a Shure microphone connected to a portable Edirol R09HR (44 kHz, 16 bit).

Rhotics were identified on the basis of visual inspection of waveforms and sonograms. They were then segmented and annotated in Praat (version 5.4.12). Following the proposal in Celata, Vietti, and Spreafico (in press), for each identified /r/-sound, we separately annotated 'constrictions' and 'apertures'. A fundamental distinction was made between rhotic sounds realized with a single consonantal gesture (a 'constriction'), and rhotic sounds realized as a combination of 'constriction' and 'aperture' gestures. In the latter case, the combination of articulatory phases can induce different types of multiple-phase rhotic segments: prototypical examples are trills, but taps can also be realized as a combination of one consonantal 'constriction' and one vocalic 'aperture', when flanked by

Figure 1: Experimental setting used for the collection of the SoPhISM corpus.

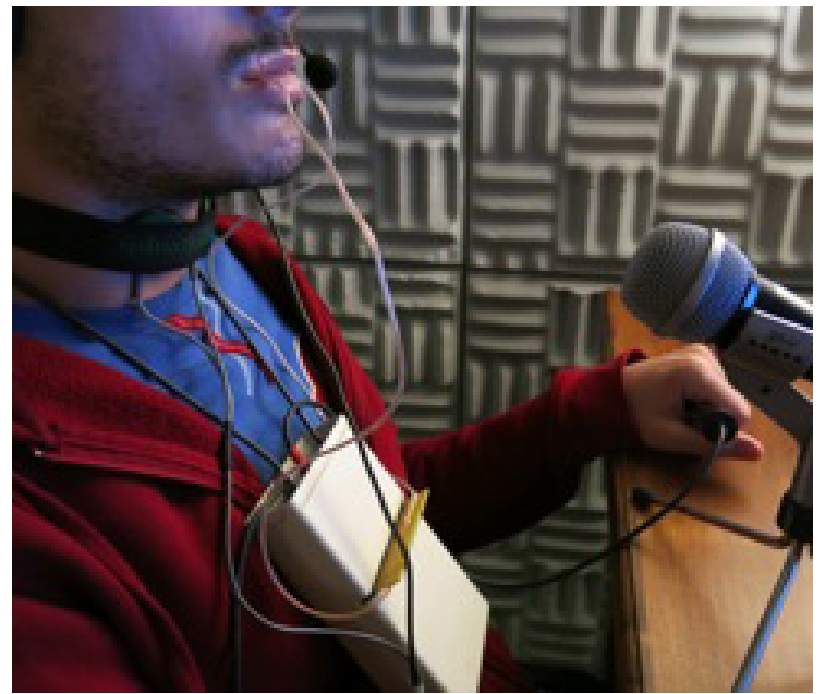


a svarabhakti vowel (or vocoid; e.g., Baltazani \& Nicolaidis, 2013; Savu, 2013). Examples of a two-phase tap and a three-phase, two-constriction trill are given in Figures 2 and 3, respectively. ${ }^{1}$ The constriction gestures in both figures are characterized by a noisy release before the aperture phase, yet for the trill, this is true for the first constriction only.

After individuation of constrictions and apertures, each rhotic segment was then categorized as a trill, tap, approximant or fricative. Fricatives are characterized by an intense aperiodic noise located at mid and high spectral frequencies. This type of rhotic realization is discussed in more detail below (see Section 4 and Figures therein). Approximants are classified as rhotics with a clearly detectable formant structure distributed over the whole duration of the segment. An example of an approximant realization is shown in Figure 4. The EPG track shows the absence of any consonantal closure before the vowel. Sometimes it was difficult to distinguish approximants from taps consisting of very long aperture phases with very short constriction phases. In such cases, a realization that could be classified as approximant during the acoustic inspection, proved to be characterized by a very short phase of full coronal closure after qualitative EPG analysis. Most of these cases were therefore re-annotated as taps (Figure 5).

Figure 2: Annotation of a two-phase (constriction + aperture) tap in the word larga 'wide'.

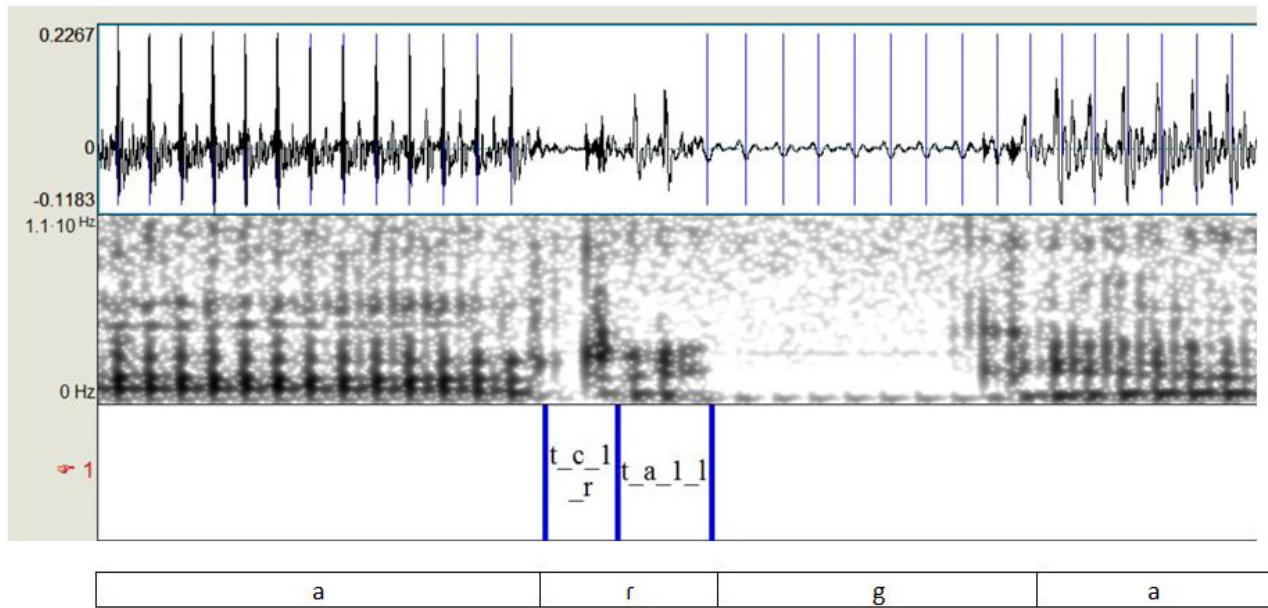

Figure 3: Annotation of the geminate rhotic as a three-phase (constriction + aperture + constriction) trill in the word sbirri 'policemen'.

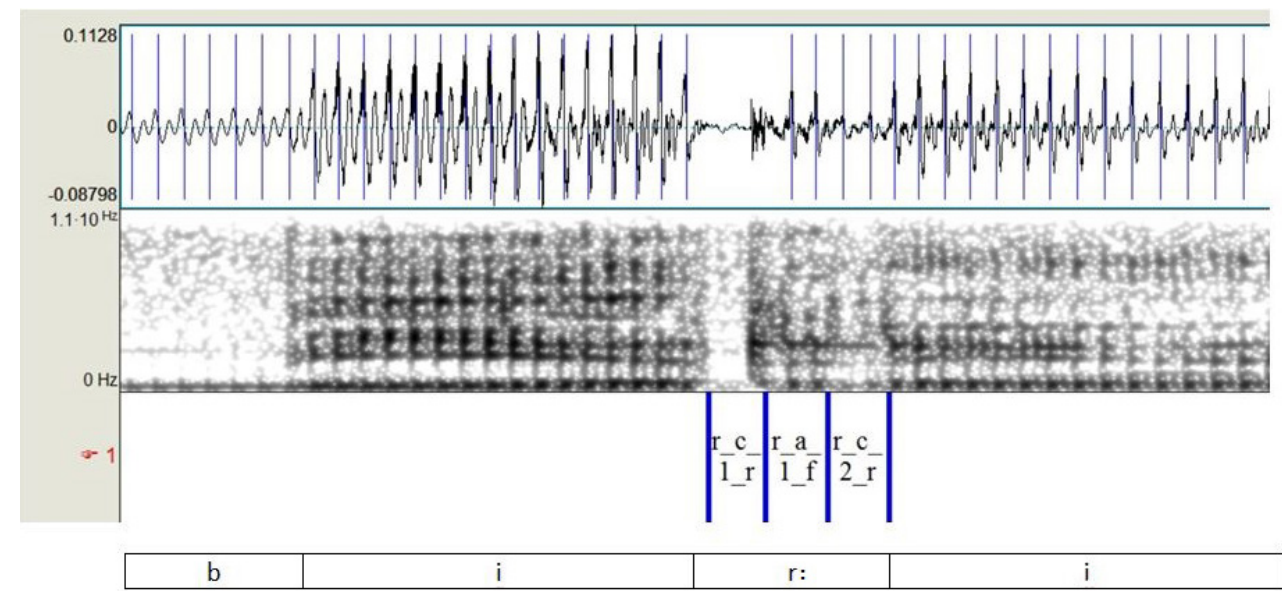

\footnotetext{
${ }^{1}$ In each figure, the acoustic waveform, spectrogram, rhotic phase annotation and phonetic IPA-style annotation of selected sounds are given. Rhotic-phase annotation is based on four different symbols separated by underscores: the first indicates whether the rhotic segment is a tap ("t"), a fricative (" $\mathrm{f}$ "), a trill (" $\mathrm{r}$ ") or an approximant ("a"); the second indicates whether the selected phase corresponds to an aperture ("a") or a constriction ("c") gesture; the third indicates whether the selected phase is the first ("1") or second ("2"), etc., aperture or constriction phase within the given rhotic segment; the fourth indicates whether an additional constriction or aperture phase follows ("r", standing for 'to the right') or precedes ("l", standing for 'to the left') or is absent ("e", standing for 'empty edges') within the same rhotic segment. From Figure 4 onwards, the EPG palatograms corresponding to the sound selection of the rhotic phase annotation are also given at the bottom.
} 
Rhotics could be included in intervocalic position as singletons or geminates, in word-initial post-pausal position, in tautosyllabic $/ \mathrm{Cr} /, / \mathrm{CCr} /$ and $/ \mathrm{sCr} /$ clusters (with $\mathrm{C}=$ a voiceless or voiced stop) and in heterosyl- labic / $\mathrm{rC} /$ clusters (with $\mathrm{c}=\mathrm{a}$ voiceless or voiced stop or $/ 1 /$ ). In the speech of Modica, however, several $/ \mathrm{rC} /$ or /lc/ clusters are produced as /CC/ (e.g., [sat:a] for sarta 'seamstress').

Figure 4: Annotation of the rhotic in the /str/ cluster as an approximant in the word lastra 'plate'.
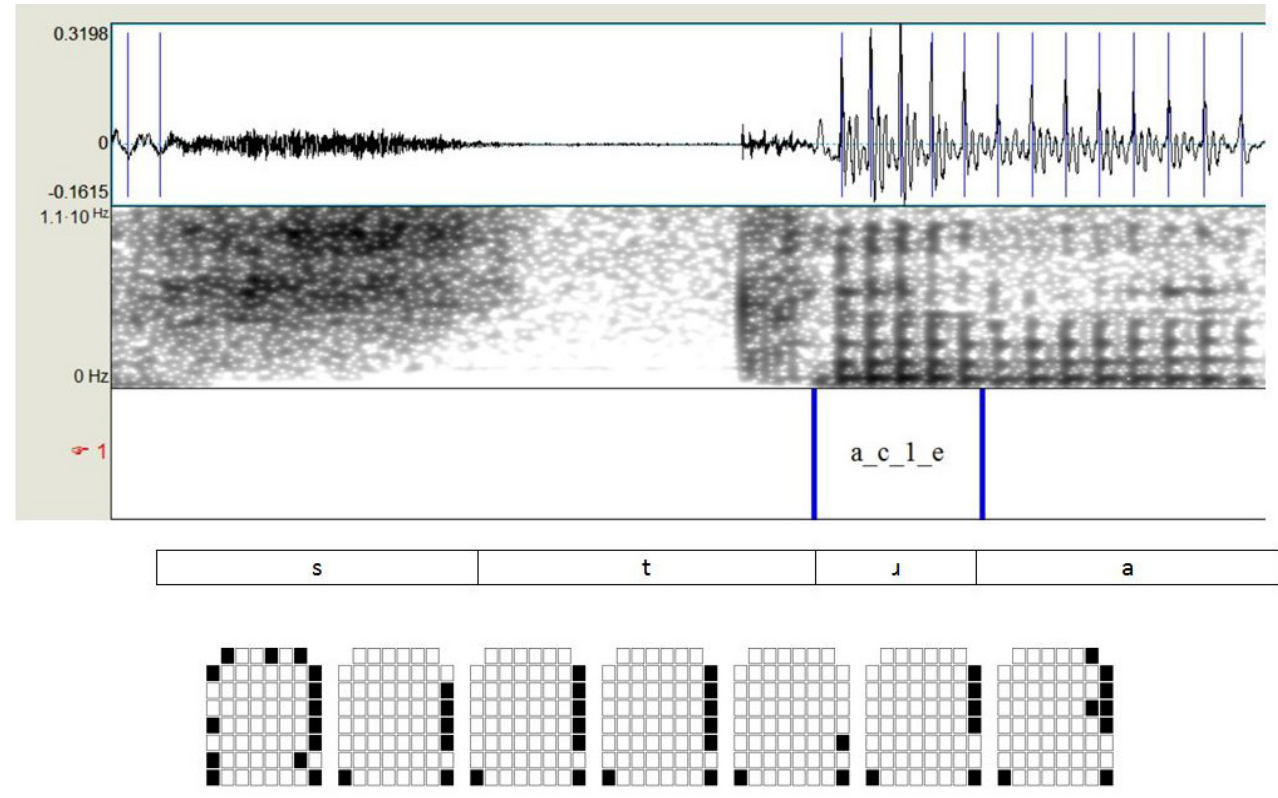

a_c_1_e

Figure 5: Annotation of the rhotic as an approximant after acoustic inspection, then corrected into a two-phase (aperture + constriction) tap after EPG qualitative inspection, in the word crudo 'raw'.
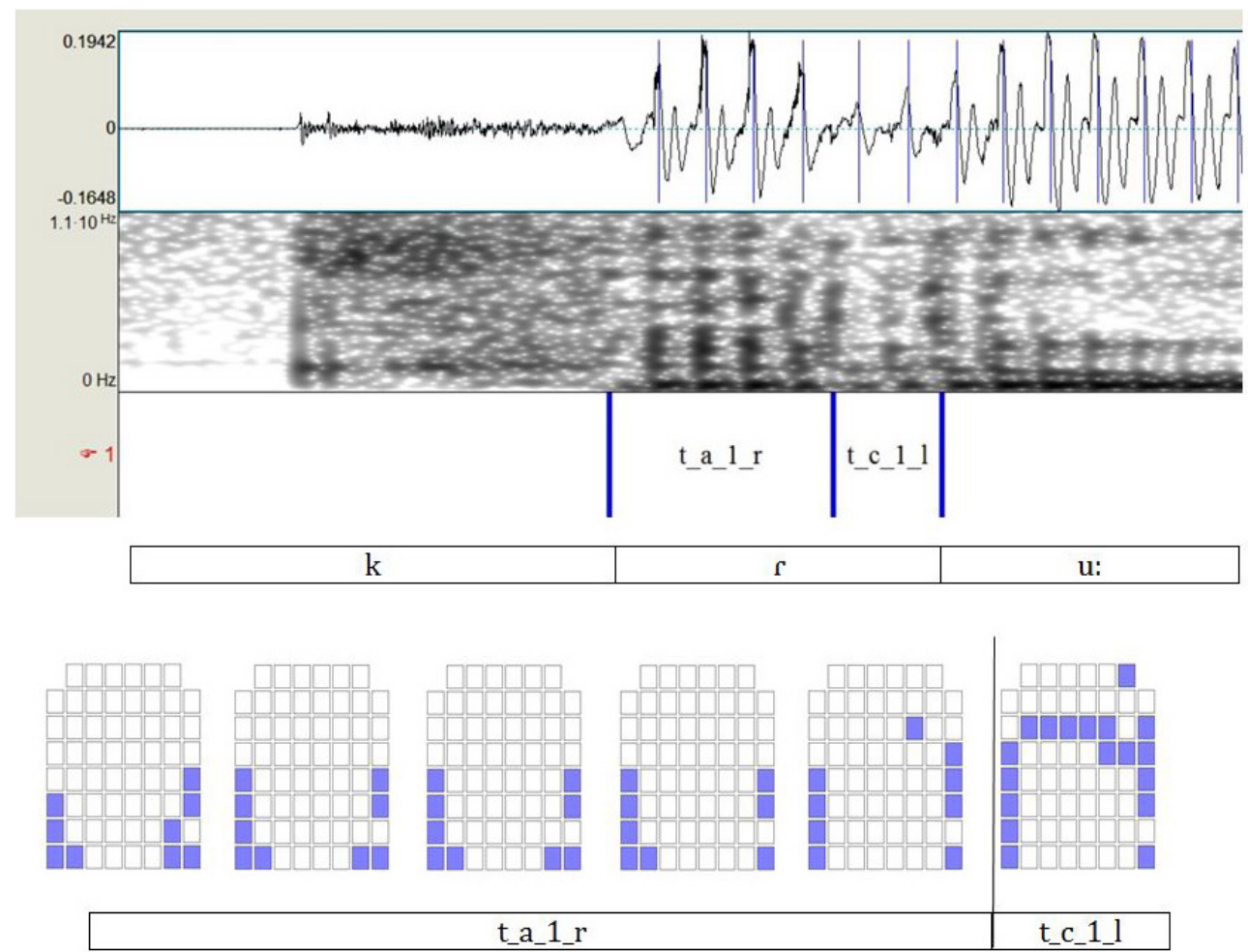


\section{RHOTIC VARIABILITY AND THE INDIVIDUAL REPERTOIRE: CHALLENGES FOR THE PHONETIC ANNOTATION OF CORPORA}

In this section we will discuss some relevant examples of variability in the production of rhotics by the speaker M1 who originates from Modica and was 28 years old at the time of the recordings. Through these examples, we will show how the annotation criteria depicted above have been adapted to cover a large spectrum of variability in the most accurate and useful way.

One aspect that is worth discussing is the realization of the opening phase in two-phase taps. In our data, the vocoid was frequently realized as either partially or completely devoiced, with a gradual loss of its formant structure. We identified several acoustic implementations of this simplification process, which span from full vocoid (no simplification) to frication noise (maximum simplification). The term 'simplification' is used here in a theoretically neutral way to signify that the vocoid is assumed to be a prototypical realization of the opening phase in two-phase taps. An example of a prototypical vocoid in a tap has been shown in Figure 2.

The figures below exemplify the variety of simplification processes, with examples taken from pre- and postconsonantal rhotics. In each figure, the upper part is the acoustic signal displaying the waveform and spectrogram, and the lower part is the EPG track which corresponds only to the portion of the acoustic signal that is comprised within the annotated intervals. Figure 6 shows a tap made of a vocoid with a non-prototypical formant structure and some aperiodic noise, followed by an equally non-prototypical constriction phase, although the EPG palatogram confirms the presence of full coronal closure in the post-alveolar zone. In Figure 7, the vocoid is even less visible and the aperture phase is substituted by a partially unvoiced, aperiodic noise. Finally, Figure 8 is an example of realizations in which the aperiodic noise reaches high intensity levels and a longer duration; in these cases, it has been annotated as a fricative segment itself. A very similar case is represented in Figure 9, in which the rhotic corresponds to a word-initial geminate. In Figure 10, one can directly compare this kind of realization of the pre-c rhotic segment in the word rinverdisce 'it becomes green again' with the typical two-phase tap as produced in a different repetition of the same word, shown in Figure 2 above.

The type of rhotic realization shown in Figures 8-10 is therefore considered to be a tap with full coronal constriction followed by a frication phase.

As can be seen, the annotation is also different from the examples in Figures 2, 6 and 7, in which the second phase of the tap is labeled as an aperture. When compared to Figures $8-10$, the second interval of the annotation is rather annotated as a fricative segment.

Figure 6: Non-prototypical tap in the word drammaturgo 'dramatist' (word onset cluster/dr/).
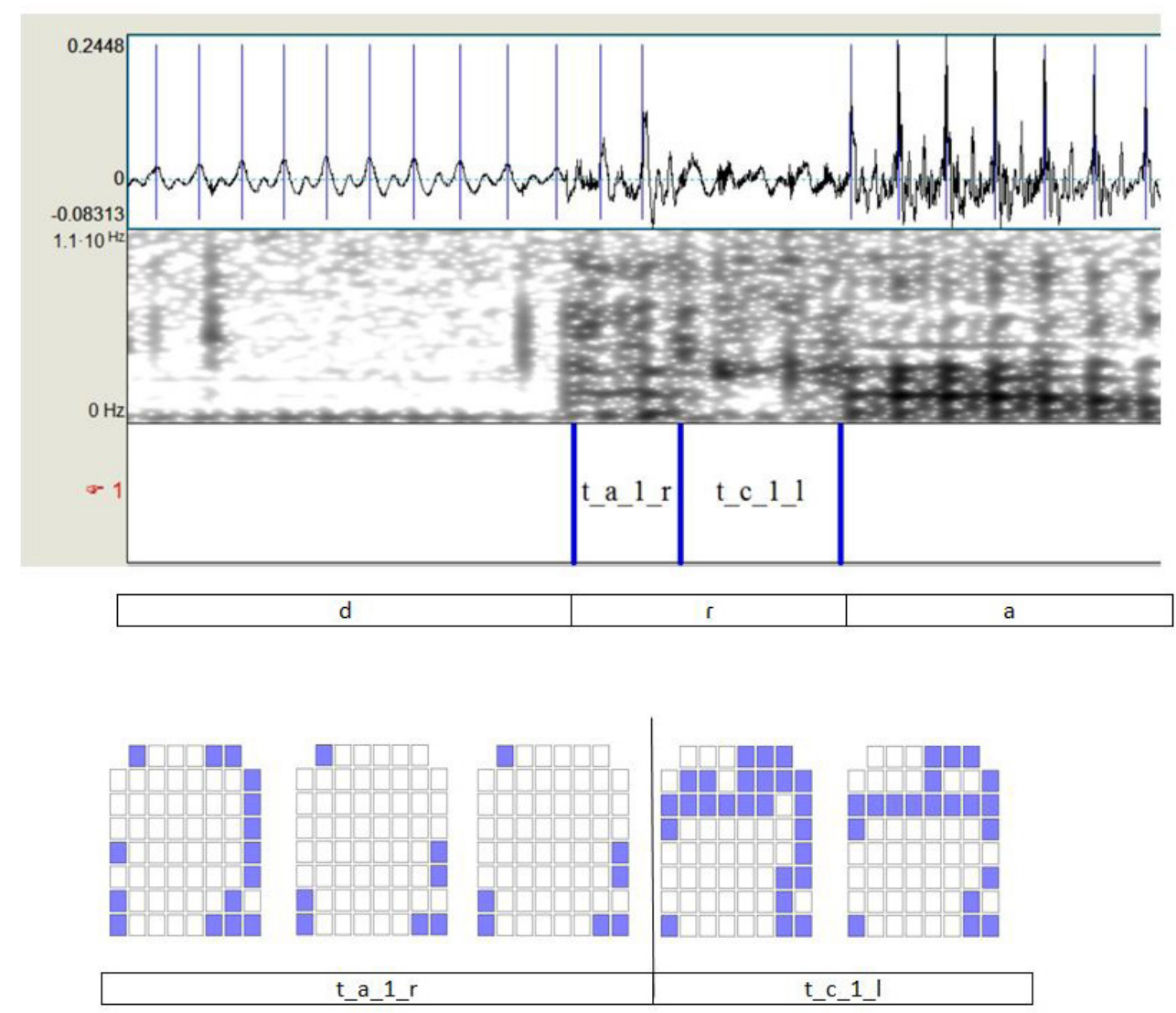
Figure 7: Tap realized as full construction followed by partially unvoiced noise in stirpi 'races, extractions'.
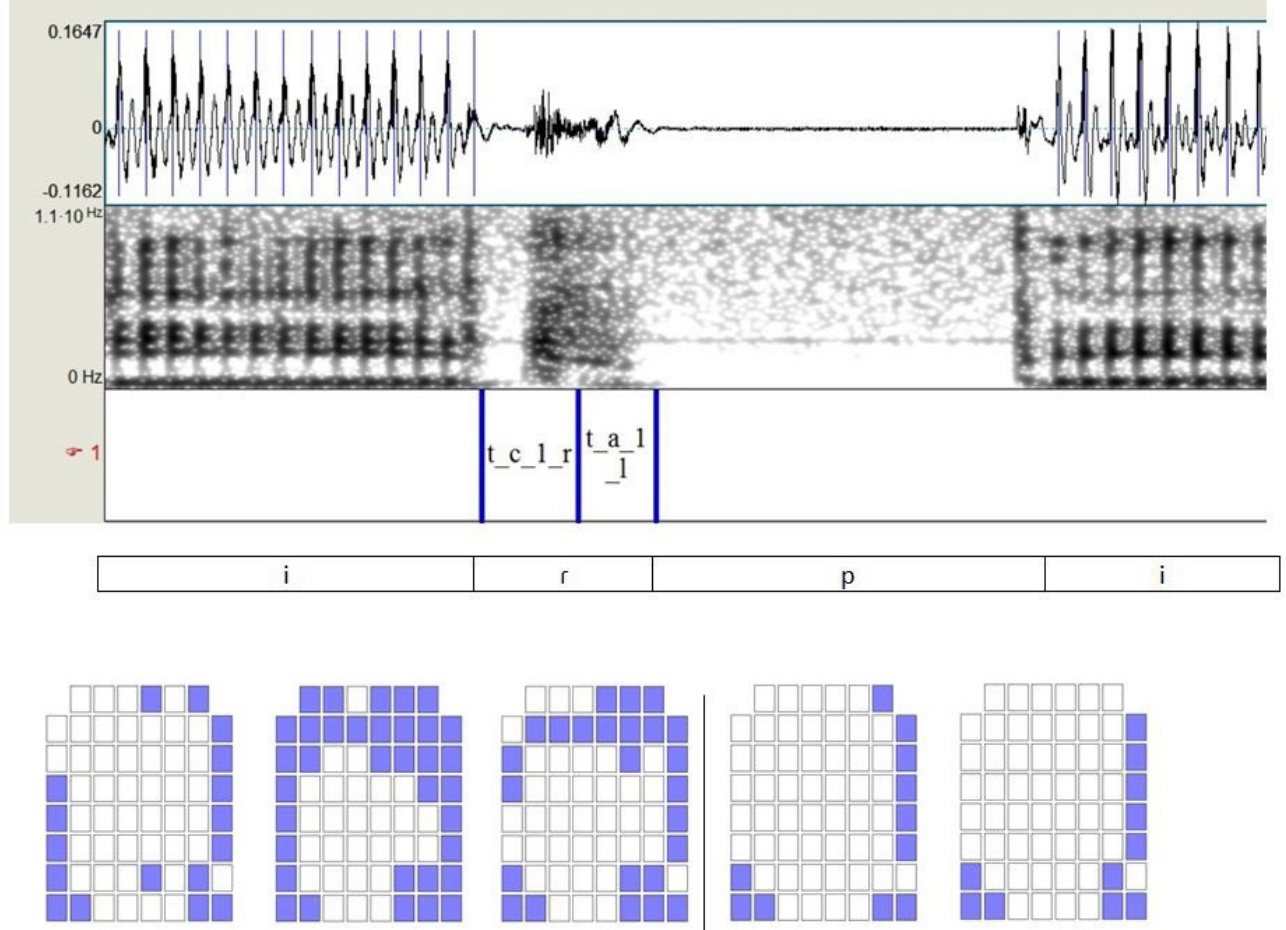

t_c_1_r

$t_{-} a_{-} 1 \_\mathrm{I}$

Figure 8: Tap constriction followed by a fricative segment in the production of mirtilli 'blueberries'.
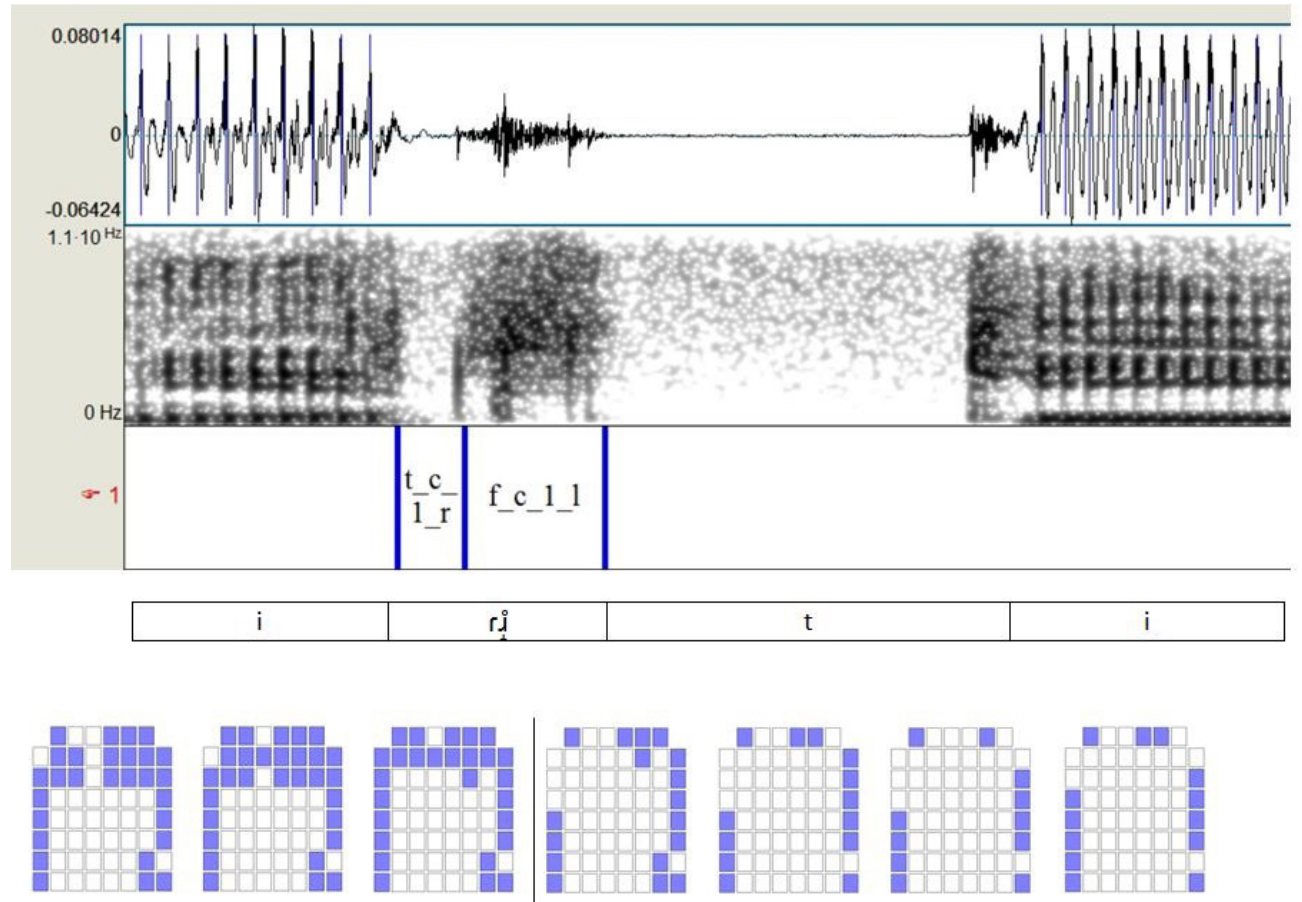

t c 1 r

f_c 1 I 
Figure 9: Tap constriction followed by a fricative segment in the production of a rugna 'scab'.
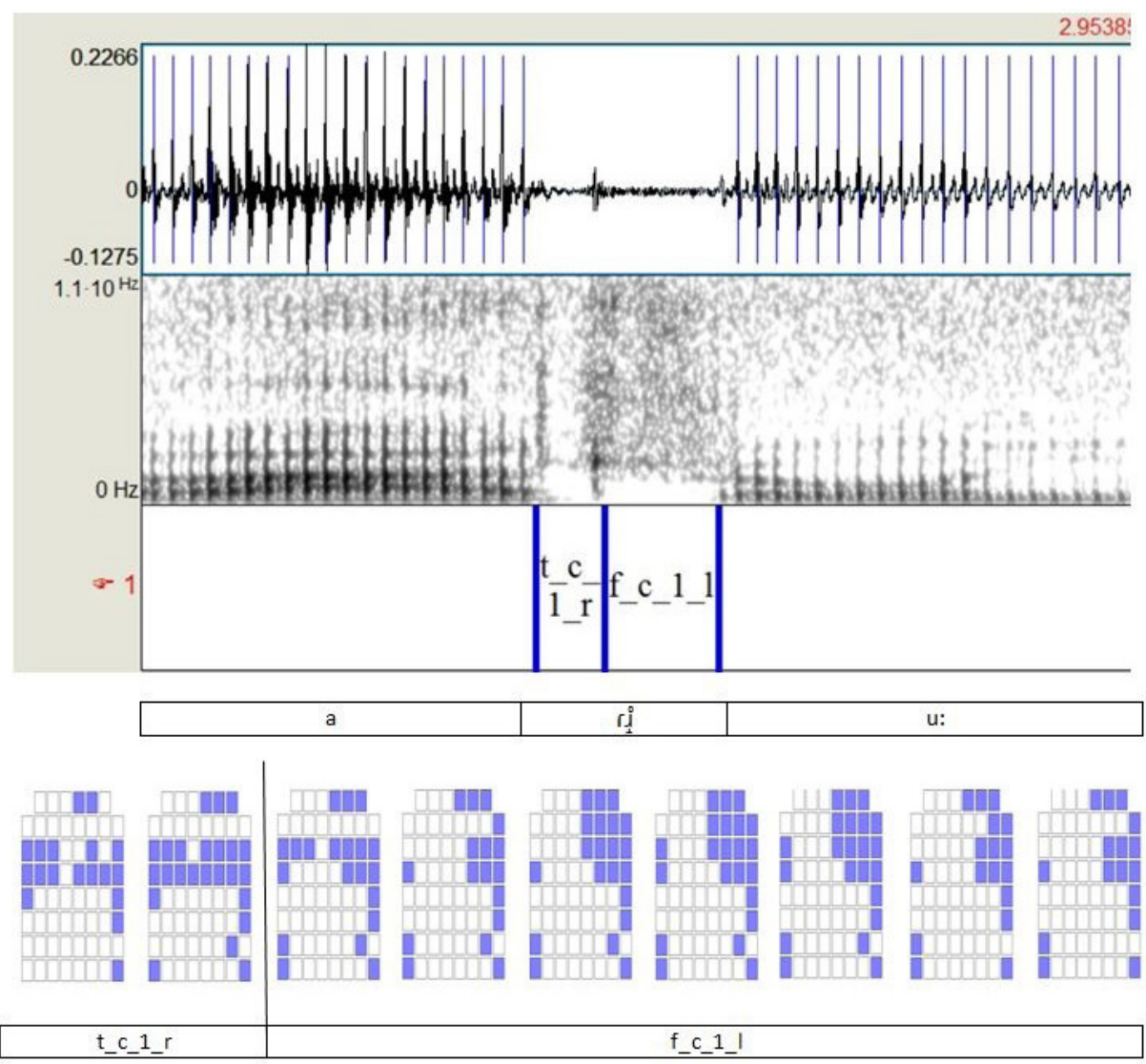

Figure 10: Tap constriction followed by a fricative segment in the production of rinverdisce 'it becomes green again'.
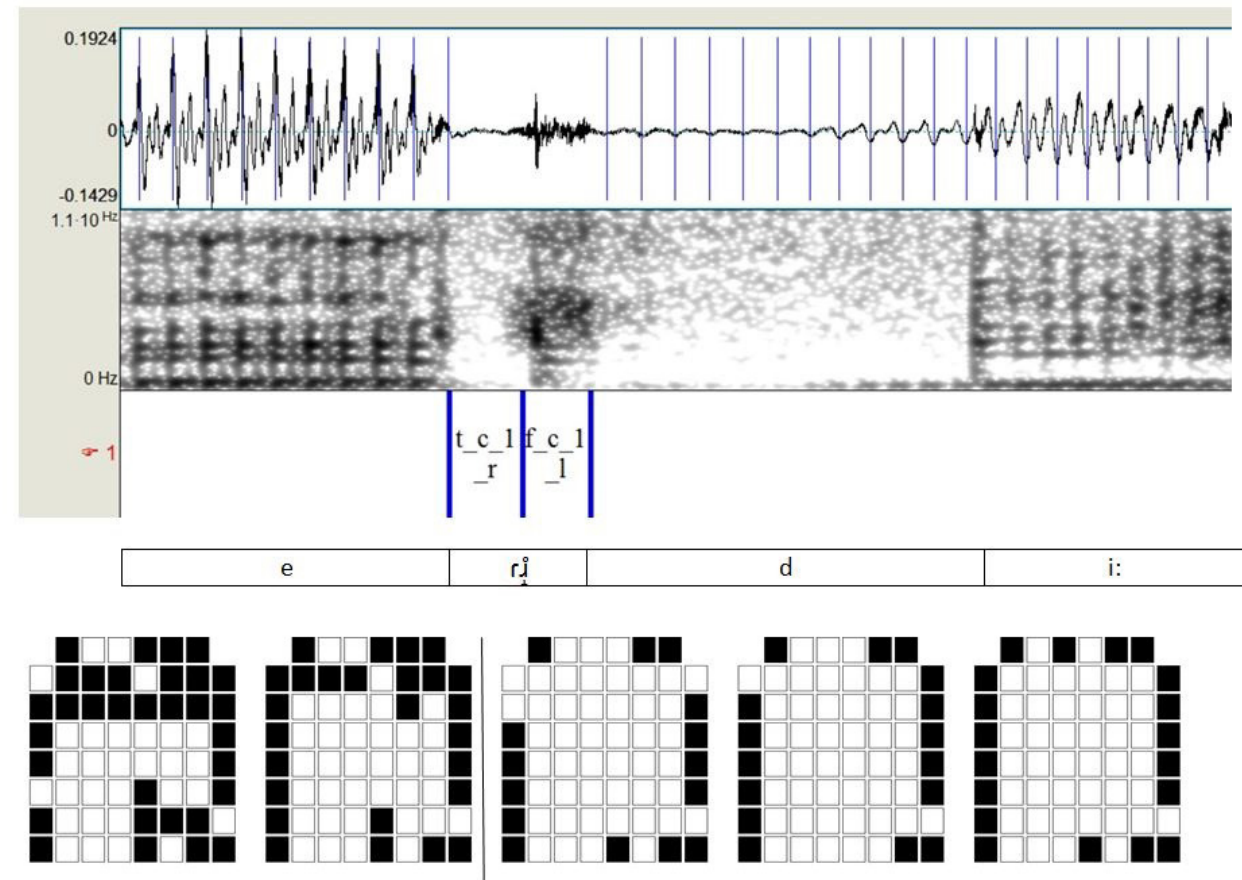

t_c_1_r

f_c_1_l 
Similar realizations have also been documented for Spanish (see Blecua, Cicres, and Gil, 2014, p. 26). They differ from typical two-phase taps but also from singlephase taps, since the rhotics are composed of two separate acoustic phases. The EPG palatograms confirm that the two phases are different even in articulatory terms. In Celata (2014), similar realizations were provisionally classified as 'spirantized taps' and indicated with the IPA symbol [r.̊]], where the symbol for the tap is followed by that for a voiceless alveolar fricative. Whether the place of articulation is alveolar or post-alveolar and whether it changes or remains stable across the two articulatory phases still has to be ascertained. Constriction location in the phase of full closure does not differ significantly from the first full contact of a trill, nor from the midpoint of [ $\left.\mathrm{z}_{i}\right]$ (see below for details on this realization); the latter is, however, more retracted than the former (Celata, 2014). ${ }^{2}$ For the moment, we only want to emphasize the presence of a full closure followed by a relatively longer, incomplete closure; the characterization of the constriction location is left to future analyses.

While the type of rhotic realization shown in Figures 8-10 is different from prototypical taps, it is also different from prototypical fricative rhotics, in which there is no full constriction at the beginning. An example of typical fricative realization of a pre-consonantal $/ \mathrm{r} /$ is shown in Figure 11. Note that the word is the same as in Figure 8, i.e., mirtilli 'blueberries'. The EPG palatograms in Figure 11 show that there is not a full closure before the partial closure of the fricative. Additionally, the fricative remains stable until the beginning of the following vocalic segment. For [ [ $: 0$.$] , the EPG analysis in Celata$ (2014) showed that there are two phases instead: a first phase in which the values of the cross-sectional alveolar closure index (Fontdevila, Pallarès, \& Recasens, 1994) are not significantly different from those of full closures in trills, and a second phase in which the values of the index are comparable to those of fricatives. The observed differences between the production of [r.̊] duction of typical fricative rhotics do not necessarily imply that the two realizations are also perceptually different. At least, this seems rather unlikely at first glance, although a systematic investigation is missing.

Most of the examples discussed so far come from the sub-corpus of Italian read speech. From this sub-corpus, the [r.̊] ] realization appears in 43 cases with 39 of them in syllable codas directly before a voiceless obstruent. This data comes from 328 total rhotics in syllable codas analyzed thus far, corresponding to $11.8 \%$ of cases. Almost all of them follow a high vowel, especially /i/ (e.g., mirtilli 'blueberries' but also tirchi 'scrooge'). There are also 3 occurrences out of 48 , corresponding to $6 \%$ of cases, in intervocalic geminate position and always in the word sbirri 'cops'. In this context, the rhotic is preferentially realized as a multiple-phase trill.

Rhotics are realized as [ri̊ cilian read speech. Here, we found 41 occurrences, 31 of which are in intervocalic position. They can stand for a geminate accounting for 24 occurrences out of the 103 geminate rhotics currently analyzed ([r.: $]$ ] representing $23 \%$ of the total geminate rhotics); they can also stand for a singleton which accounts for 7 occurrences out of the 184 singletons analyzed so far (4\%). Additionally, in word-initial position there is a total of 10 occurrences out of $70(14 \%)$. Note that word-initial rhotics are long in Sicilian. Thus the [r.̊] variant in the sub-corpus of Sicilian read speech is preferentially found where a long rhotic is expected. As already anticipated, there are no $\mathrm{r}+\mathrm{C}$ heterosyllabic clusters in the Sicilian production of subject M1, since these clusters are normally assimilated ( $\mathrm{rC}, \mathrm{lc}>\mathrm{C}$ :).

The Italian and Sicilian sub-corpora of read speech therefore differ when attesting the [ri̊n] realization in different phonotactic contexts: there is a preference for singletons in coda position in Italian, and a preference for long segments in prevocalic position in Sicilian. In Italian, however, the percentage of occurrences is much lower. Another difference concerns the average duration: according to our measurements, the Italian [r. I ] is on average shorter than in Sicilian, about $27 \mathrm{~ms}$ (55 vs. $82 \mathrm{~ms}$ ). Yet in both sub-corpora there is a strong preference for [r.̊.] appear close to a high vowel: overall, 63 of the total 84 occurrences were close to /i/, 21 close to /u/. In articulatory terms, high vowels being produced with anterodorsum raising are notoriously antagonistic to trills (Recasens, 2012; Recasens \& Pallarès, 1999; Solé, 2002), and they also induce large v-to-c coarticulatory effects on taps (e.g., Celata, Vietti, \& Spreafico, in press; Recasens \& Pallarès, 1999). [ [̊̊̊l] could therefore be seen as one of the results of such an articulatory conflict in the case of trills, or coarticulatory adjustment in the case of taps, which has previously been labeled as a 'simplification' of the canonical rhotic form. The fully fricative realization [ $\left.\mathrm{z}_{i}\right]$ could additionally be seen as one step further in the process of solving the articulatory divergence between trills and high vowels. However, the apparently different distribution of [r.̊.] in the two SoPhISM sub-corpora suggests that, in spite of the common phonetic context, [ [ $\left.0_{1}^{0}\right]$ is one of the allophonic surface forms of geminate $/ \mathrm{r}$ :/ in Sicilian, and of coda $/ \mathrm{r} /$ in Italian. This is nothing but a working hypothesis, which should be tested with a larger data sample. If confirmed, this pattern would represent an interesting case of within-subject variation in which one and the same phonetic form, [rị] , is harnessed by a speaker with two different phonological functions (i.e., to signal two different contextual allophones) in different speech varieties of his native repertoire.

2 A geminate postalveolar fricative is said to be the normal realization of /r:/ in intervocalic, word-internal position in Sicilian (e.g., Ruffino, 2001; it is usually referred to as a sibilant, and for this reason the provisional annotation was [z; in Celata, 2014). According to the dialectological literature, this feature is typical of the dialect and does not spread to Sicilian accented Italian. As shown immediately below,

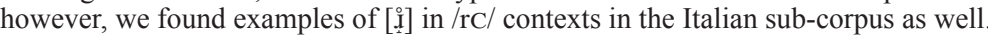


Figure 11: Pre-consonantal rhotic realized as a fricative in the production of mirtilli 'blueberries'.

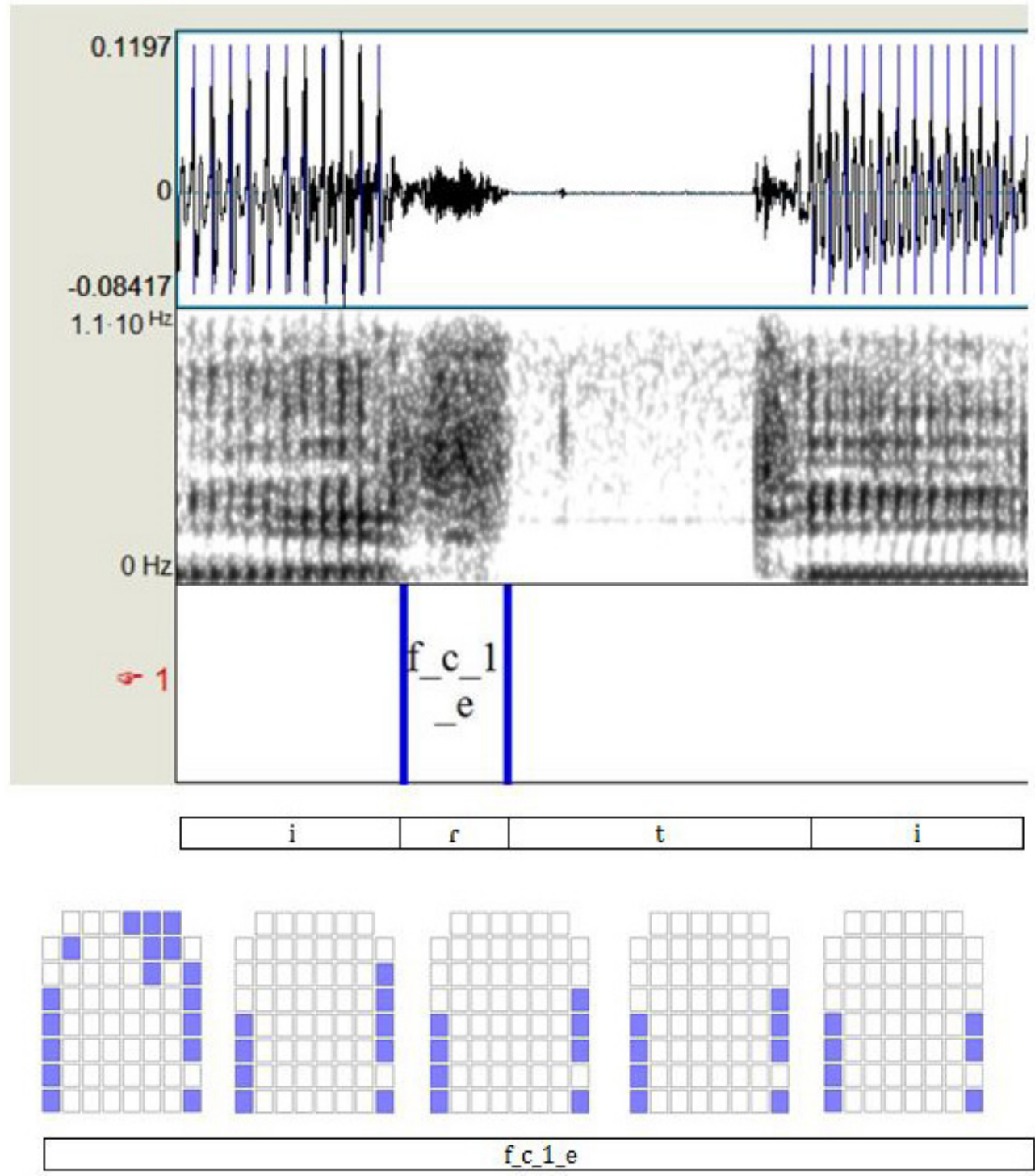

\section{RHOTIC VARIABILITY AND THE \\ INDIVIDUAL REPERTOIRE: THE SPEAKERS' USE OF THE FRICATIVE VARIANTS}

We now focus on the distribution of both fully fricative rhotics $[\mathrm{z}(\mathrm{i})]$ and spirantized rhotics [ri̊] , considered together as one class of fricative variants or allophones of $/ \mathrm{r} /$. The reason the two realizations are considered together as one rhotic variant is that, as previously mentioned, we do not think that the two realizations are perceptually distinct.

Analyzing the distribution of fricative allophones in the corpus can shed light on possible regularities arising from external factors such as speech task, setting formality and identity of the interlocutor; this should provide evidence in support of, or against, the hypothesis that, in addition to phonetic factors, sociolinguistic and communicative factors also play a role in the selection of rhotic variants.
We analyzed the distribution of the fricative variant in the speech of M1 which includes both Italian and Sicilian sentence lists and Italian and Sicilian dialogues with the two of the three Is. The speech of two interlocutors, I1 and I2, was also analyzed. As explained $\mathrm{n}$ Section 3, the two interlocutors were friends of M1, one from childhood and the other from adolescence. Both are of Sicilian origin, but only I1 was born and raised in the same town of M1.

The incidence of the fricative variant in the different sub-corpora is shown in Table 1. It displays the variant as a percentage of the total occurrences with respect to the total occurrences of rhotics produced by the relevant speaker in the applicable sub-corpus. For instance, fricative rhotics as a realizations of /r:/ in the read Italian speech of M1 equal 10\% of his total /r:/ productions from the Italian sentence list. 
Table 1: Percentages of occurrence of the fricative variant in the speech of M1 and of two of his interlocutors (I1 and I2).

\begin{tabular}{|c|c|c|c|c|}
\hline Speaker & Task & (V)r:V & VrC & VrV \\
\hline \multirow{4}{*}{ M1 } & Ita-Reading & $10 \%$ & $16 \%$ & - \\
\hline & Sic-Reading & $40 \%$ & - & $18 \%$ \\
\hline & Ita-Maps with I1 & $9 \%$ & $25 \%$ & - \\
\hline & Sic-Maps with I1 & $30 \%$ & - & $8 \%$ \\
\hline \multirow[t]{2}{*}{ I1 } & Ita-Maps & $14 \%$ & $17 \%$ & - \\
\hline & Sic-Maps & $21 \%$ & - & $8 \%$ \\
\hline & Ita-Maps with I2 & $10 \%$ & $80 \%$ & - \\
\hline & Sic-Maps with I2 & $70 \%$ & - & $4 \%$ \\
\hline \multirow[t]{2}{*}{$\mathrm{I} 2$} & Ita-Maps & 0 & $41 \%$ & - \\
\hline & Sic-Maps & - & - & - \\
\hline
\end{tabular}

Overall, the fricative variant appears to be more frequent in Italian than in Sicilian speech (I2 is the exception, as he produces fricatives only when speaking Italian). In Sicilian, there is a preference for the fricative variant to occur in the context of intervocalic geminates and word-initial long rhotics. This is distinct from Italian which gives a preference for the coda position. This trend confirms what has been found for the distribution of [ [r. I $]$ in read speech.

The dialectological literature consistently reports that long word-initial and intervocalic /r:/ in the Sicilian dialects is realized as [zi] (see Section 4, footnote 2). However, in our data, the choice of [ $\left.z_{i}\right]$ for $/ \mathrm{r}: /$ in Sicilian is never categorical, thus indicating that $/ \mathrm{r}$ :/ can be produced as non-fricative as well. In addition, the fricative variant is equally possible in other, non-geminate contexts in Sicilian; most surprisingly, the fricative variant is also present in Italian read speech and dialogues.

There is a general increase in the use of the fricative variant in informal speech / dialogues as compared to sentence reading. There is also a noticeable increase in the use of the fricative variant in I2's dialogues in comparison to I1's. This effect is equally strong in Italian and Sicilian dialogues. M1 appears to spirantize a greater majority $(80 \%)$ of pre-c rhotics when speaking Italian, and a lesser majority $(70 \%)$ of long pre-vocalic rhotics when speaking Sicilian with I2. In the former case, there seems to be a connection with the high incidence of fricatives in the speech of the interlocutors $(41 \%$ of pre-c rhotics are produced as fricatives by I2). Unfortunately for prevocalic geminates, it was impossible to determine the production preferences of $\mathrm{I} 2$, due to the paucity of the data analyzed to date.

In conclusion, the analysis suggests that M1 selects the fricative variant according to the phonetic context as outlined in the previous section, as well as for communicative requirements such as speech style and the pronunciation features of his interlocutor. Further analyses will be necessary in order to ascertain the presence of a significant correlation between the phonetic choices of one individual and those of his/her interlocutors for different rhotic variants and for a sufficiently large number of speakers.

\section{GENERAL DISCUSSION AND FUTURE PERSPECTIVES}

The SoPhISM corpus allows acoustic and articulatory analyses of intra-speaker variation as a function of stylistic and communicative factors in the speech of young dialectal speakers from a southern Sicilian area. Since the research project based on SoPhISM is still in progress, the analysis proposed here is intended to show the potential of the articulatory sociophonetic approach and to serve as a reminder of how complicated a small dataset of phonetic data can be.

In fact, our analysis confirms the high degree of variation characterizing the production of rhotics from the perspective of within-subject variation. We have proposed a set of descriptive parameters that can be used for the finegrained annotation of rhotics, particularly emphasizing the distinction between constrictions and apertures. These annotation parameters are able to capture most aspects of variation in atypical rhotic realizations and explain them in terms of phonetic derivations, or simplifications, of typical closure-aperture sequences.

In particular, we have shown that rhotics can be realized as short full closures followed by a relatively longer frication phase, which we have provisionally transcribed as [r.̊․] This is most likely due to changes in the articulatory properties of the aperture phase(s) in pre-c taps and prevocalic trills adjacent to high vowels. Future analyses will have to discern the precise acoustic and articulatory properties of similar multiple-phase realizations. Since constriction + frication rhotics have been sporadically noticed in previous work with Spanish speech corpora (e.g., Blecua et al., 2014), we are compelled to further ascertain the articulatory and acoustic features that distinguish this kind of realization from other rhotic variants, with the ultimate aim 
of making predictions on possible sound changes involving a modification of the constriction-aperture dynamics. Moreover, the annotation scheme proposed here is potentially usable for cross-linguistic annotation of corpora including different languages, a practice that should improve our understanding of the basic articulatory and acoustic ingredients of rhotic variation and change.

Our study also shows that a detailed phonetic knowledge about the surface manifestations of rhotic segments is a necessary precondition to understand the dynamics of sociophonetic variation underpinning the speakers' selection of variants for their stylistic, social or communicative needs.

In this respect, the proposed analysis of the distribution of fricative variants in the repertoire of M1 and of some of his interlocutors is aimed at showing the possibilities provided by SoPhISM for the study of sociophonetic variation at the micro level of the idiolects of individual speakers. Although more analysis and data are needed, this preliminary inspection has shown that, contrary to what has been claimed by the dialectological literature, the fricative variant is not confined to dialectal use, but also surfaces in less formal, regionally accented Italian. Moreover, the distribution of the variant in the dialect and in Sicilian Italian is partly different with respect to those phonotactic contexts in which the variant preferentially surfaces. This suggests that the speaker can fluctuate in his/her manipulation of the same phonetic features, to serve different purposes in different varieties of his/her speech repertoire. This reinforces the view that the idiolect of Italo-Romance dialectal speakers as a continuum of stylistic/communicative varieties, rather than as a juxtaposition of several available linguistic codes as it is in 'true' bilinguals.

As Foulkes, Scobbie, and Watt (2010, p. 706) state, the "indexical functions of a linguistic variable are usually manifested in statistical differences in a form's distribution across speakers, groups, or speech styles, rather than resulting from categorical usage or non-usage of a particular variant". The categorical "usage or non-usage" of a given form is truly what characterizes a linguistic variety with respect to another. Our data appears to be consistent with the hypothesis that the use of the fricative variants of ' $R$ ' has indexical purposes, being featured by "statistical differences in [the] form's distribution", rather than manifesting a categorical opposition between a 'dialectal $/ \mathrm{r} /$ ' and an 'Italian $/ \mathrm{r} /$ '. When the complexity of the idiolect is taken into consideration and intra-speaker variation is analyzed as a function of stylistic or communicative functions, much of what has been traditionally referred to as cross-linguistic, or geographic, differentiation turns out to be interpretable in terms of sociophonetic variation within the individual repertoire.

The dynamics and functions of such sociophonetic variation of rhotics in the repertoire of contemporary young adult Sicilians have yet to be fully characterized. What we hope to have shown here is that sociophonetic corpora focused on individual variation are likely to be useful instruments for such characterization.

\section{ACKNOWLEDGMENTS}

This research was supported by Scuola Normale Superiore Grant N ${ }^{\circ}$ 750/GR13 “Modeling Speech Variation in Socio-Communicative Context" to the first author, who also takes responsibility for drafting Sections 1, 2, 4 and 6 of the present paper; the second author takes responsibility for having performed the annotation of the SoPhISM corpus and for Sections 3 and 5 of the paper; the third author takes responsibility for having taken care of the instrumental setting during the recordings and for the preprocessing of the articulatory data.

\section{REFERENCES}

Alfonzetti, G. (2013). Il polylanguaging: una modalità di sopravvivenza del dialetto nei giovani. Bollettino. Centro Studi Filologici e Linguistici Siciliani, 24, 213-251.

Ammon, U. (2003). On the social forces that determine what is standard in a language and on conditions of successful implementation. Sociolinguistica, 17, 1-10. http://dx.doi.org/10.1515/ 9783110245226.1

Auer, P. (2005). Europe's sociolinguistic unity, or: A typology of European dialect/standard constellations. In N. Delbecque, J. van der Auwera \& D. Geeraerts (Eds.), Perspectives on variation. Sociolinguistic, historical, comparative (pp. 7-42). Berlin: Mouton de Gruyter. http://dx.doi.org/10.1515/9783110909579.7

Baltazani, M., \& Nicolaidis, K. (2013). The many faces of /r/. In L. Spreafico \& A. Vietti (Eds.), Rhotics. New data and perspectives (pp. 125-143). Bolzano: Bolzano University Press.

Barbu, S., Martin, N., \& Chevrot, J.-P. (2014). The maintenance of regional dialects: a matter of gender? Boys, but not girls, use local varieties in relation to their friends' nativeness and local identity. Frontiers in Psychology, 5, 1-11. http://dx.doi.org/ 10.3389/fpsyg.2014.01251

Berruto, G. (1987). Sociolinguistica dell'italiano contemporaneo. Roma: La Nuova Italia Scientifica.

Berruto, G. (1989). Tra italiano e dialetto. In G. Holtus, M. Metzeltin \& M. Pfister (Eds.), La dialettologia italiana oggi: Studi offerti a Manlio Cortelazzo (pp. 107-122). Tübingen: Narr.

Blecua B., Cicres, J., \& Gil, J. (2014). Variación en las róticas del español y su implicación en la identificación del locutor. Revista de Filología Románica, 31, 13-35.

Celata, C. (2006). Analisi dei processi di retroflessione delle liquide in area romanza, con dati sperimentali dal còrso e dal siciliano. PhD dissertation, Scuola Normale Superiore di Pisa. Retrieved from http://linguistica.sns.it/tesi/celata/tesi Celata.htm

Celata, C. (2014). Per una sociofonetica sperimentale delle lingue romanze: La variabile (r) a Modica. In Atti del XIII Convegno Internazionale della SILFI (Società Internazionale di Linguistica e Filologia Italiana). Palermo, CSFLS.

Celata, C., Vietti, A., \& Spreafico, L. (in press). An articulatory account of rhotic variation in Tuscan Italian: Synchronized UTI and EPG data. In J. Gil \& M. Gibson (Eds.), Romance Phonetics and Phonology. Oxford: Oxford University Press.

Cerruti, M. (2011). Regional varieties of Italian in the linguistic repertoire. International Journal of the Sociology of Language, 210, 9-28. http://dx.doi.org/10.1515/ijsl.2011.028

Cerruti, M., Crocco, C., \& Marzo, S. (Eds.) (in press) Towards a new standard. Theoretical and empirical studies on the restandardization of Italian. Berlin: de Gruyter Mouton.

Coseriu, E. (1980). 'Historische Sprache' und 'Dialekt'. In J. Göschel, P. Ivić \& K. Kehr (Eds.), Dialekt und Dialektologie. Ergebnisse des internationalen Symposions 'Zur Theorie des Dialekts', Marburg/Lahn, 5-10. September 1977 (pp. 106-122). Wiesbaden: Steiner. 
Coupland, N., \& Kristiansen, T. (Eds.) (2011). Standard Languages and Language Standards in a Changing Europe. Oslo: Novus.

Crocco, C. (in press). Everyone has an accent. Standard Italian and regional pronunciation. In M. Cerruti, C. Crocco \& S. Marzo (Eds.), Towards a new standard. Theoretical and empirical studies on the restandardization of Italian. Berlin: de Gruyter Mouton.

D’Agostino, M., \& Paternostro, G. (2013). Parlanti e società dall'Unità ai nostri giorni in Sicilia. In Ruffino, G. (ed.), Lingua e cultura in Sicilia (pp. 1-81). Palermo: Centro Studi Filologici e Linguistici Siciliani.

Dal Negro, S., \& Vietti, A. (2011). Italian and Italo-Romance dialects. International Journal of the Sociology of Language, 210, 71-92. http://dx.doi.org/10.1515/ijs1.2011.031

De Pascale, S., Marzo, S., \& Speelman, S. (2016). Indirect and direct measurement of attitudes toward regional varieties of Italian: A change in standard language ideology? Paper presented at Sociolinguistics Symposium 21, Murcia, 15-18 June, 2016.

Eckert, P. (2012). Three waves of variation study: The emergence of meaning in the study of variation. Annual Review of Anthropology, 41,87-100.http://dx.doi.org/10.1146/annurev-anthro-092611145828

Felloni, M. C. (2011). Prosodia sociofonetica. L'italiano parlato e percepito a Parma. Pavia: FrancoAngeli.

Fontdevila, J., Pallarès, M.D., \& Recasens, D. (1994). The contact index method of electropalatographic data reduction. Journal of Phonetics, 22, 141-154.

Foulkes, P., Scobbie, J.M., \& Watt, D. (2010). Sociophonetics. In W. J. Hardcastle, J. Laver \& F. E. Gibbons (Eds.), Handbook of Phonetic Sciences (2nd ed.), pp. 703-716. London: Blackwell. http://dx.doi.org/10.1002/9781444317251.ch19

Giles, H. (1994). Accommodation in Communication. In R. E. Asher (Ed.), Encyclopedia of language and linguistics, Vol. I (pp. 12-15). Oxford: Pergamon.

Johnstone, B., Andrus, J., \& Danielson, A. E. (2006). Mobility, indexicality, and the enregisterment of "Pittsburghese". Journal of
English Linguistics, 34(2), 77-104. http://dx.doi.org/10.1177/ 0075424206290692

Lawson, R. (2011). Patterns of linguistic variation among Glaswegian adolescent males. Journal of Sociolinguistics, 15(2), 226255. http://dx.doi.org/10.1111/j.1467-9841.2011.00477.x

Meluzzi, C. (2014). Le affricate dentali nell italiano di Bolzano. Un approccio sociofonetico. PhD dissertation, Università di Pavia.

Meluzzi, C. (2016). A new sonority degree in the realization of dental affricates /ts dz/ in Italian. In M. J. Ball \& N. Müller (Eds.), Challenging sonority: Cross-linguistic evidence from normal and disordered language. London: Equinox.

Mendoza-Denton, N. (2008). Homegirls: Language and cultural practice among Latina youth gangs. Oxford: Wiley-Blackwell. http://dx.doi.org/10.1002/9780470693728

Nodari, R. (in preparation). L'italiano degli adolescenti: Aspirazione delle occlusive sorde in Calabria e percezione della varietà locale. $\mathrm{PhD}$ dissertation, Scuola Normale Superiore di Pisa.

Recasens, D. (2012). Coarticulation in Catalan dark /1/ and the alveolar trill: General implications for sound change. Language and Speech, 56(1), 45-68. http://dx.doi.org/10.1177/ 0023830912440790

Recasens, D., \& Pallarès, M.D. (1999). A study of $/ \mathrm{r} /$ and $/ \mathrm{r} /$ in the light of the 'DAC' coarticulation model. Journal of Phonetics, 27, 143-169. http://dx.doi.org/10.1006/jpho.1999.0092

Ruffino, G. (2001). Sicilia. Roma: Laterza.

Savu, C.-F. (2013). Another look at the structure of [r]: Constricted intervals and vocalic elements. In L. Spreafico \& A. Vietti (Eds.), Rhotics. New data and perspectives (pp. 145-158). Bolzano: Bolzano University Press.

Scobbie, J. (2006). (R) as a variable. In Brown, K. (Ed.), Encyclopedia of Language \& Linguistics (2nd ed.), pp. 337-344. Oxford: Elsevier. http://dx.doi.org/10.1016/B0-08-044854-2/04711-8

Wrench, A. A. (2007). Advances in EPG palate design. Advances in Speech Language Pathology, 9(1), 3-12. http://dx.doi. org/10.1080/14417040601123676 